\title{
Analysis of personality traits as a risk factor in crash related trauma.
}

Vineet Kumar, Rahul Goyal, Ajai Singh, Vineet Sharma, Rajeshwer Nath Srivastava,Santosh Kumar, Ashish Kumar

Department of Orthopaedic Surgery, King George's Medical University, Lucknow, Uttar Pradesh, India- 226018.

\begin{abstract}
:
Background: Due to increasing stress, individual personality traits are becoming a significant contributor to CRT (Crash Related Trauma). In the present study, we hypothesized that there will be no difference in personality characteristics of CRT patients and control subjects and there will be no association between trauma and personality characteristics of CRT patients.

Method: A total of 119 cases and 112 controls of age $>18$ years were selected as per criteria decided. After obtaining ethical clearance, patients presenting to the emergency orthopedic unit were included in the study. After primary management all enrolled subjects were assessed by ICD 10 module screening questionnaire and analyzed for nine personality traits, subject to written informed consent.

Results: Of all the cases enrolled $82.35 \%$ were males. Impulsive personality trait is found in $84.78 \%(39 / 46)$ cases. There were 46 motorcyclists out of 119 cases enrolled. Most of the personality traits showed a statistical significant association $(p<0.0003)$ with CRT.

Conclusion: Majority of CRT victims attending orthopedic emergency unit at trauma center had impulsive and histrionic personality characteristics which accounted for $84.78 \%$ and $82.61 \%$ cases respectively. These traits showed a statistical significant association with CRT.

Keywords: Crash related trauma, personality traits, motorcyclist.

DOI: http://dx.doi.org/10.4314/ahs.v16i3.27

cite as: Kumar V, Goyal R, Singh A, Sharma V, Srivastava RN,Kumar S, Kumar A. Analysis of personality traits as a risk. factor in crash related trauma. Afri Health Sci 2016;16(3): 845-852. DOI: http://dx.doi.org/10.4314/abs.v16i3.27.
\end{abstract}

\section{Introduction}

Crash Related Trauma (CRT) or Road Traffic Accidents (RTA) constitutes a major bulk of non-communicable diseases in the present era ${ }^{1}$. They account for around $25 \%$ of all deaths from injuries across the globe according to WHO records ${ }^{2}$. The statistics for India are appealing. In India, CRT alone accounts for $63.64 \%$ of cases of all the injured ${ }^{3}$. CRT constitutes the major cause of misery, disability, and deaths worldwide with a disproportionate number occurring in developing countries ${ }^{4-6}$. It has been estimated that by 2020, CRTs will rank as high as third amongst the causes of disability adjusted life years lost $t^{6-8}$. Most of the CRTs occur in urban regions in developing countries and pedestrians and motorcyclists collec-

\section{Corresponding author:}

Ajai Singh

Department of Orthopaedic Surgery

King George's Medical University,

Lucknow, Uttar Pradesh, India - 226003.

Phone No.- +919415022557

Email: as29762@gmail.com tively constitute around $70-90 \%$ of deaths due to road traffic injuries. Urban pedestrians account for $55-70 \%$ of deaths?.

The frequency of these crash related trauma, should be determined by the risk inherent in the activity and/or the situation and should be reflected in a pattern established for chance happenings. When a frequency distribution for these CRT's is analyzed, there are a number of individuals who have a greater proportion of CRT than can be explained by chance alone ${ }^{10}$.

Researchers ${ }^{11}$, suggest that individuals having difficulty related to personal and social demands of living will tend to make repeated driving errors. The term "accident proneness" was proposed in the 1920's to account for the disproportionate distribution of accidents amongst drivers with similar exposure. Proponents of the Accident Proneness Model $^{12}$ hypothesized that personality traits rather than individual differences in psychomotor ability determine which individuals are involved in accidents when the exposure to risk is equal ${ }^{12-14}$.

Certain elements of psychological factors cause the lawbreaking behaviors including the personality traits such as 
impulsiveness, affectivity, extraversion, individual differences, social and attitudinal factors ${ }^{15}$.

Personality characteristics such as impulsivity and adventurousness, aggressiveness, inability to tolerate authority and control hostility, being indifferent to the rights of others, preoccupation with fantasy satisfaction, fear of loss of love and support, inability to tolerate tension, poor self-control and guilt-proneness have been reported to occur frequently in drivers ${ }^{16}$.

Generally, the studies ${ }^{17}$ indicate that individuals with aggressiveness, impulsiveness, depression, anxiety and extroversion are the 'long term repeaters' for CRTs. Although the evidences is sketchy till now, there seems to be a certain consistency in the traits described as crash related when personality differences are identified. The 'shortterm accident repeaters' have been described as possibly suicidal and self-destructive or undergoing temporary life stresses or undergoing an "accident process." This recent concept emphasizes that temporary life stresses cause personality deterioration in individuals and thus lead to CRT. Personality is a moderator between stimuli and behavior. Personality traits may explain the different reactions of different individuals when faced with the same situation. So, it seems logical that differences in personality characteristics of individuals, without any psychiatric illness ${ }^{18}$ may result in differing tendencies for CRT. Also, if personality characteristic differences in CRT patients are identified, it could be inferred that differences in various personality characteristics of individuals may lead to CRT proneness.

Hence, in the present study, we worked on two research questions:

1) Whether there was any difference in personality characteristic of RTA cases and control subjects?

2) Whether there was any association between mode of causation of trauma and personality characteristics? For this we formulated two null hypothesis as-

1) There will be no difference in personality characteristics of RTA patients and control subjects; and 2) There will be no association between mode of causation of trauma and personality characteristics of RTA patients. So, we conducted this study to evaluate the patterns of non-fatal orthopaedic injuries in CRT patients attending a tertiary care center and to find their association with the various personality characteristics of the injured patients.

\section{Material and methods}

The study included fully conscious and oriented patients of $>18$ years, suffering from non-fatal orthopaedic injuries (taken as those cases who were conscious, fully oriented in time, place and person and did not require any intensive measure at the time of presentation, as these subjects could safely and reliably be subjected to screening procedure) as a result of CRT and attending orthopedic emergency unit, trauma center of a tertiary referral center, subject to written informed consent. The patients for this study were enrolled on only two days in a week which was decided prior to the study. The duration of enrolment was August 2014 to July 2015. Patients with significant psychiatric illness, under the influence alcohol or other drugs that could alter his/ her alertness were excluded from the study. The attendants of the cases with similar socio-economic profile and matched for their age and sex, except injury were taken as controls. Controls were non trauma subjects who gave informed consent without any psychiatric illness and intake of drugs that could alter their alertness. This study was a hospital based open ended case control study.

After the ethical approval from institutional ethics committee and written informed consent, all cases were clinically assessed and managed accordingly. Thereafter all the cases and controls satisfying our inclusion - exclusion criteria were given a personality assessment questionnaire, namely International Personality Disorder Examination ICD-10 Module Screening Questionnaire ${ }^{19,20}$. Our study primarily involved North Indian population where Hindi is the primary language for conversation. In our questionnaire, therefore we used the Hindi version of the questionnaire which is validated as per the study performed by Sharan $\mathrm{P}$ et $\mathrm{al}^{21}$. The study population was capable of understanding the local language although not all were literate enough to read it. The patients who were not able to read were assisted by a trained resident who performed the evaluation as per questionnaire under the guidance of a qualified clinical psychologist.

Nine personality characteristics diagnosed in response to screening questionnaire were studied in both cases and controls and association of any of these characteristics with CRT was evaluated for statistical significance. All the statistical tests were performed with graph Pad prism 5.0 software. Chi square test was used to determine the significance of difference in the two groups. 


\section{Results}

In this study we registered a total of 119 cases and 112 controls as per inclusion-exclusion criteria. There were 82.35\% males (98/119). Of all patients 38.66\% were motorcyclists (46/119). Fractures constituted 94.95\% $(113 / 119)$ of total injuries , of which $61.34 \%(69 / 112)$ were closed and in that too $45.75 \%(97 / 212)$ were lower limb fractures with $\mathrm{AO}$ sub-type $42 \mathrm{~A}$ having the most frequent occurrence. Various personality traits in cases and controls were assessed with the help of standard screening questionnaire and their frequency of occurrence is shown in Table 1 . Of all the CRT occurring in motorcyclists, $84.78 \%(39 / 46)$ cases were associated with their impulsive personality trait.

Table-1: Personality characteristics of CRT cases and control subjects

\begin{tabular}{|l|l|l|l|l|l|l|l|l|}
\hline $\begin{array}{l}\text { Personality } \\
\text { characteristics }\end{array}$ & $\begin{array}{l}\text { Pedestrian } \\
(\mathbf{3 3})\end{array}$ & $\begin{array}{l}\text { Motorcyclists } \\
(\mathbf{4 6})\end{array}$ & $\begin{array}{l}\text { LMVD } \\
\mathbf{( 1 2 )}\end{array}$ & $\begin{array}{l}\text { HMVD } \\
(\mathbf{2 8})\end{array}$ & $\begin{array}{l}\text { Total } \\
\text { number } \\
\text { of cases } \\
(\mathbf{1 1 9})\end{array}$ & $\begin{array}{l}\text { Percentage } \\
\text { of } \\
\text { (\%) }\end{array}$ & $\begin{array}{l}\text { Number } \\
\text { of } \\
\text { controls } \\
(\mathbf{1 1 2})\end{array}$ & $\begin{array}{l}\text { Percentage of } \\
\text { controls (\%) }\end{array}$ \\
\hline Paranoid & 23 & 28 & 6 & 9 & 66 & 55.46 & 45 & 40.18 \\
\hline Schizoid & 10 & 3 & 1 & 3 & 17 & 14.28 & 23 & 20.53 \\
\hline Dissocial & 17 & 34 & 6 & 22 & 79 & 66.39 & 29 \\
\hline Impulsive & 23 & 39 & 8 & 15 & 85 & 71.43 & 29 \\
\hline Borderline & 17 & 28 & 8 & 14 & 67 & 56.30 & 24 \\
\hline Histrionic & 21 & 38 & 9 & 14 & 82 & 68.91 & 25 \\
\hline Anankastic & 12 & 15 & 2 & 4 & 33 & 27.73 & 33 \\
\hline Anxious & 16 & 25 & 5 & 12 & 58 & 48.73 & 78 \\
\hline Dependent & 12 & 11 & none & 9 & 32 & 26.89 & 57 \\
\hline
\end{tabular}

LMVD: Light Motor Vehicle Drivers; HMVD: Heavy Motor Vehicle Drivers

We analyzed the personality characteristics of cases and controls, and statistical significance of their presence in cases as compared to controls by applying chi-square test as shown in Table-2. 
Table-2: Personality characteristics of CRT cases and controls

\begin{tabular}{|l|l|l|l|}
\hline Personality characteristics & Cases & Controls & p-value \\
\hline Paranoid & 66 & 45 & 0.2023 \\
\hline Schizoid & 17 & 23 & 0.3093 \\
\hline Dissocial & 79 & 29 & $0.0002^{*}$ \\
\hline Impulsive & 85 & 29 & $<0.0001^{*}$ \\
\hline Borderline & 67 & 24 & $<0.0003^{*}$ \\
\hline Histrionic & 82 & 25 & $<0.0001^{*}$ \\
\hline Anankastic & 33 & 33 & 0.8893 \\
\hline Anxious & 39 & 78 & $<0.0001^{*}$ \\
\hline Dependent & 26 & 57 & $<0.0001^{*}$ \\
\hline
\end{tabular}

*Significant

It is inferred that persons with personality characteristics like impulsiveness, borderline, dissocial, histrionic and paranoid were significantly associated $(\mathrm{p}<0.0003)$ with CRT when compared with normal control subjects and personality characteristics of anxiety and dependency were protective in nature showing a statistically significant negative association.

On analyzing the personality traits in motorcyclists encountering CRT by applying chi-square test (Table -3), we found that dissocial, histrionic and impulsive traits were shown to have statistical significant association with CRT amongst cases and controls i.e these traits are pro-trauma in motorcycle riders whereas cases with schizoid, anankastic, anxious and dependent traits showed a statically negative association, meaning that these traits are protective in nature, thus preventing CRT's in motorcyclists as they are seen significantly more common in controls. It is inferred that persons with personality characteristics like impulsiveness, borderline, dissocial and histrionic were significantly associated with CRT when compared with normal control subjects and personality characteristics of anxiety and dependency were protective in nature showing a statistically significant association. 
Table- 3: Personality characteristics of motorcyclists CRT victims

\begin{tabular}{|l|l|l|l|l|}
\hline $\begin{array}{l}\text { Personality } \\
\text { characteristics }\end{array}$ & Present & Absent & $\begin{array}{l}\text { Percentage } \\
\%\end{array}$ & p-value \\
\hline Paranoid & 28 & 18 & $60.87 \%$ & 0.159 \\
\hline Schizoid & 3 & 43 & $6.52 \%$ & $<0.0001^{*}$ \\
\hline Dissocial & 34 & 12 & $73.91 \%$ & $0.001^{*}$ \\
\hline Impulsive & 39 & 7 & $84.78 \%$ & $<0.0001^{*}$ \\
\hline Borderline & 28 & 18 & $60.87 \%$ & 0.159 \\
\hline Histrionic & 38 & 8 & $82.61 \%$ & $<0.0001^{*}$ \\
\hline Anankastic & 15 & 31 & $32.61 \%$ & $0.018^{*}$ \\
\hline Anxious & 14 & 32 & $30.43 \%$ & $0.007^{*}$ \\
\hline Dependent & 6 & 40 & $13.04 \%$ & $<0.0001^{*}$ \\
\hline
\end{tabular}

*Significant

Dissocial personality characteristic is 5-6 times strongly associated with cases compared to controls, impulsive and histrionic personality characteristics are 7 times more strongly associated to cases compared to controls whereas anxious and dependant personality characteristics were $1 / 5$ times associated with cases compared to controls (Table- 4). 
Table-4: Personality characteristics of CRT cases and controls

\begin{tabular}{|l|l|l|l|l|l|}
\hline $\begin{array}{l}\text { Personality } \\
\text { characteristics }\end{array}$ & Cases & Controls & p-value & Odd's ratio & Confidence interval \\
\hline Paranoid & 66 & 45 & 0.2023 & 1.854 & $0.998-3.128$ \\
\hline Schizoid & 17 & 23 & 0.3093 & 0.644 & $0.324-1.284$ \\
\hline Dissocial & 79 & 29 & $0.0002^{*}$ & $5.653^{*}$ & $3.200-9.980$ \\
\hline Impulsive & 85 & 29 & $<0.0001^{*}$ & $7.155^{*}$ & $4.004-12.787$ \\
\hline Borderline & 67 & 24 & $<0.0003^{*}$ & $4.724^{*}$ & $2.648-8.428$ \\
\hline Histrionic & 82 & 25 & $<0.0001^{*}$ & $7.712^{*}$ & $4.273-13.920$ \\
\hline Anankastic & 33 & 33 & 0.8893 & 0.918 & $0.518-1.626$ \\
\hline Anxious & 39 & 78 & $<0.0001^{*}$ & $0.212^{*}$ & $0.121-0.370$ \\
\hline Dependent & 26 & 57 & $<0.0001^{*}$ & $0.269^{*}$ & $0.152-0.477$ \\
\hline
\end{tabular}

*Significant

\section{Discussion}

In real life scenario, some people are prone to CRT by virtue of multiple factors which probably define personality traits of the individual in some way. These traits are of equal importance in all situations where CRT's may occur, the implication being that a comparatively small group of individuals is responsible for the majority of such trauma.

The quality of motives, feelings, attitudes, beliefs and value system and a set of individual and social behaviors could be considered as the major factor in traffic phenomenon. In this regard, the personality and psychological characteristics of drivers, conditions governing the cognitive field and their emotional, behavioral and sensory- motor feelings could play the highest role in traffic and CRT.

In our study, majority of CRT victims attending orthopedics emergency unit at trauma center were having impulsive and histrionic personality characteristics which accounted for $71.43 \%$ and $68.91 \%$ cases respectively. Other common personality characteristics of CRT victims were paranoid, dissocial and borderline personality characteristics which were present in $55.46 \%, 66.39 \%$ and $56.30 \%$ cases respectively. Schizoid, dependent, anxious and anankastic personality characteristics were relatively rarer where as in control subjects who were attendants of CRT victims, anxious personality characteristic was most common (69.64\%) followed by dependent and paranoid personality characteristic in $50.89 \%$ and $40.18 \%$ controls respectively. Other personality traits like impulsiveness, histrionic trait, dissociative behavior, and borderline traits were relatively rare in controls.

To the best of our knowledge, no study has been done in reference to the parameter of our study. People have tried to correlate various types of personalities, personality traits, and behavior with many other aspects of CRT and its proneness in the past. Jonah ${ }^{15}$ in a meta-analysis of 40 studies found that only 4 studies did not find significant positive relationships between Sensation Seeking (SS) and some aspect of risky driving. Overall, Jonah evidenced that high sensation seeker patients were more likely to experience collisions and violations than low sensation seekers. In our study, sensation seeking as a personality trait was not considered as it is not defined by the ICD10 module screening questionnaire. On contrary, persons with impulsiveness and histrionic personality characteristic were more prone to CRT probably due to loss of selfcontrol. Histrionic trait in some way pertains to sensation seeking trait and is defined as a melodramatic behavior designed to attract attention. Thus our study findings are 
in accordance with and are well supported by the study conclusion of Jonah et al. Our study also seeks support from Blanchard, Barton and Malta ${ }^{22}$ who analyzed amongst different personality traits that SS trait is a good predictor of self-reported driving violations.

Our study findings support the observations of Manglam $\mathrm{M} \mathrm{K}$ et al. ${ }^{23}$ who found significantly higher frequency of breaking rules, crossing speed limits and a trend towards a higher frequency of carrying extra persons (i.e., more than recommended) in accident-prone drivers. Histrionic personality trait followed by dissocial trait constitutes all these tendencies of CRT proneness and in our study had a significant positive association with CRTs. They also observed that emotional lability was more common in crash prone drivers, which is in accordance with borderline personality characteristic of our study. Apprehension was described as a protective trait by them where as anxiety as a trait in our study also revealed a negative association with CRTs and anxiety in a way pertains to apprehension.

Further, in our study, majority of motorcyclists who were CRT victims were having predominance of impulsive and histrionic personality characteristics accounting for $84.78 \%$ and $82.61 \%$ cases respectively followed by antisocial, paranoid and borderline personality characteristics which were $73.91 \%, 60.87 \%$ and $60.87 \%$ respectively and least common personality trait type was schizoid. Our study further seeks its support from the study findings of Beirness, D.J. ${ }^{24}$ who found that one factor accounting for crash involvement was a reduced capacity to manage or control hostility. He observed that the greatest numbers of traffic CRT were reported by a subgroup characterized by aggressive and un-socialized tendencies. This pertains in our study that having an impulsive personality characteristic prone for CRTs.

Thus we conclude that individuals with certain personality characteristics are prone to CRT. We recommend that these individuals may be identified and counseled at the time of disbursing of driving licenses; which in turn may lead to a lower prevalence of CRT. However determinants of CRT include a combination of environmental, vehicle and human factors. Other factors also need to be studied and controlled to make a significant reduction in the prevalence of road traffic accident prevalence.
Our study is limited by its small sample size, included patients from a single center, limitations of IPDE ICD10 module screening questionnaire and the fact that we limited our study to only non-fatal injuries. Limitations of IPDE ICD-10 questionnaire include the assumption that a person is capable of providing a valid description of disturbances in his personality. However, an individual may be unaware of some of his traits.

He or she may also be resistant to acknowledging behavior, if it is socially undesirable or if he thinks its disclosure is likely to adversely affect his best interests. This is especially likely to occur in patients who wish to terminate treatment prematurely, or in those about to be discharged from a mental health facility. Others may exaggerate disturbances in their behavior. This is sometimes observed in those who are frantically seeking help, or who are dissatisfied with their treatment or the amount of attention they are receiving. It may also be a reflection of certain personality traits.

Multi-centric studies including other relevant emergency surgical specialties, with larger sample size are further needed to gather strong support and validate the findings of our study. We would definitely like to stress upon the fact that the causation of CRT is multi-factorial and in this study we have focused only on one aspect (personality trait) of it, which might be one of the possible associations and should not definitely be attributed as a sole cause for it.

We also have not included or measured any driving behaviors like breaking rules, crossing speed limits and trend towards a higher frequency of carrying extra persons. So we also recommend further studies taking into consideration the above mentioned parameters for future research and better understanding of injury patterns in CRT.

\section{Acknowledgments}

The authors thank Dr. Rakesh Kumar Tripathi (Assistant Professor, Department of Geriatric Mental health, KGMU, Lucknow) for their excellent technical assistance and support to conduct the study.

\section{Conflict of interest}

None 


\section{References}

1. Park, K., Park's Textbook of Preventive and Social Medicine, 20th ed. Jabalpur: Banarsi Das Bhanot; 2009.

2. Peden, M., McGee, K., Sharma, G., The injury chartbook: A graphical overview of the global burden of injuries. Geneva: World Health Organization, 2002.

3. Verma, V., Singh, S., Singh, G.K., Kumar, S., Singh, A., Gupta, K., Distribution of Injury and Injury Patterns in Trauma Victims Admitted to the Trauma Center of CSMMU, Lucknow. Indian Journal of Community Health; 2013. 25 (1): 52-60

4. Tiwari, G., Mohan, D., Muskang, R., Mumbai urban transport project 2: Accident study. 1-342. New Delhi: TRIPP, Indian Institute of Technology Delhi. Final report prepared for World Bank; 1998

5. Nantulya, V.M., Reich, M.R., The neglected epidemic: Road traffic injuries in developing countries. BMJ. 2002. 324:1139-41.

6. Lagarde, E., Road traffic injury is an escalating burden in Africa and deserves proportionate research efforts. PLoS Med. 2007;4:e170.

7. Ghaffar, A., Hyder, A.A., Masud, T. I., The burden of road traffic injuries in developing countries: The first national survey of Pakistan. Public Health. 2004. 118: 211-7.

8. Museru, L.M., Leshabari, M.T., Road traffic accidents in Tanzania: A 10-year epidemiological appraisal. East Cent Afr J Surg. 2002; 7:23-6.

9. Nantulya, V.M., Muli $\neg$ Musiime, F., Kenya: Uncovering the social determinants of road traffic accidents. In: Challenging inequities: from ethics to action. Oxford: Oxford University Press, 2001, Order URL: http://worldcat.org/ isbn/0195137396

10. U. S. Congress. Motor Vehicle Traffic Conditions in the U. S., the Accident Prone Driver. House Document, No. 462, Part VI, Washington, D. C., Government Printing Office, p. 110; Crancer, A., Jr. and D. Quiring, .The Mentally III as Motor Vehicle Operators. American Journal of Psychiatry, 1969. 126: p. 807-813.

11. Feldman, M. P., Man Drives as He Lives - Psychological Factors in Road Accidents. Automobile Engineer, 1967: p. 508-509

12. H. M. Johnson., Biographical Methods of Deterring Accident Prone Drivers. Psychological Bulletin, 1938. 35: p. 511-512.
13. Crancer, A., Involvement of the Problem Driver in Motor Vehicle Accidents. Traffic Quarterly, 1967. 21: p. 601-610.

14. Gerald, H., Whitlock, Robert, J., Clouse, W.F.S., Predicting Accident Proneness.Personnel Psychology, 1963.16(1): p. 35-44.

15. Jonah B.A., Sensation seeking and risky driving: A review and synthesis of the literature. Accid Anal Prev., 1997.29: p. 651-665.

16. Tillmann, W.A., Hobbs, G.E., The accident prone automobile driver; a study of the psychiatric and social background. Am J Psychiatry, 1949. 106(5): p. 321-31

17. McGuire, S.F.L., A Typology of Accident Proneness. Behavioral Research in Highway Safety, 1970; 1(1): p. 26-32.

18. Dan, J. S., Katharine, A. P., Derek, B., Fulford K.W.M, John, Z.S., Kenneth S.K., What is a Mental / Psychiatric Disorder? From DSM-IV to DSM-V. Psychological Medicine (London: Cambridge University Press), 2010. 40(11): p.1759-1765.

19. Assessment and diagnosis of personality disorders: the international personality disorder examination (IPDE)/ edited by Armand W. Loranger, Aleksandar Janca, and Norman Sartorius. 2007. http://apps.who.int/iris/bitstr eam/10665/41912/1/9780521041669.pdf.

20. Loranger AW, Sartorius N, Andreoli A, berger, P, et al. The world Health Organization/Alcohol, drug Abuse and Mental Health Administration International Pilot study of Personality disorders. Archives of General Psychiatry, 1994. 51:215-24.

21. Sharan P, Kulhara P, Verma SK, Mohanty M. "Reliability of the ICD-10 international personality disorder examination(IPDE) (hindi version): a preliminary study." Indian J Psychiatry. 2002 Oct; 44(4):362-4.

22. Blanchard, E.B., Barton, K.A., Malta L., Psychometric properties of a measure of aggressive driving: The Larson Driver's Stress Profile. Psychological Reports.2000. 87: p. 881-892.

23. Manglam, M. K., Sinha, V.K., Praharaj, S.K., Bhattacharjee, D., Das, A., Personality correlates of accidentproneness in auto-rickshaw drivers in India. Int J Occup Saf Ergon, 2013.19(2): p.159-165

24. Beirness, D.J., Do We Really Drive As We Live? The Role of Personality Factors in Road Crashes. Alcohol, Drugs and Driving, 1993.9(3-4): p.129-143. 